\title{
Genoa, Italy Bridge Collapse: Effects on Neonatal Emergency Transport Service
}

\author{
Carlo Bellini, MD, $\mathrm{PhD} ;^{1} \oplus$ Maria Grazia Calevo ${ }^{2}$
}

1. Neonatal Emergency Transport Service, IRCCS Istituto Giannina Gaslini, Genoa, Italy

2. Epidemiology, Biostatistics and Committees Unit, IRCCS Istituto Giannina Gaslini, Genoa, Italy

\section{Correspondence:}

Carlo Bellini, MD, $\mathrm{PhD}$

Neonatal Emergency Transport Service Department of Mother \& Child IRCCS Gaslini

Via G. Gaslini, 5

16147 Genoa, Italy

E-mail: carlobellini@gaslini.org

\section{Conflicts of interest: none}

Received: February 8, 2019

Accepted: March 31, 2019

doi:10.1017/S1049023X19004503

Bellini C, Calevo M. Genoa, Italy bridge collapse: effects on neonatal emergency transport service. Prehosp Disaster Med. 2019;34(4):458-459.

To the Editor,

The Genoa Morandi bridge collapse (Genoa, Italy) in August 2018 had wide echoes in the international press; ${ }^{1-4}$ it was a human tragedy, killing 43 people, and an economic disaster for Genoa, a city of some 580,000 inhabitants and the first Mediterranean port. Beyond its vital role for the metropolitan area of Genoa, the Morandi Bridge was inserted in a viability system crucial for the whole northwest of Italy. The bridge carried the A10 highway, running along the coastline to the France border, passing hundreds of tunnels, bridges, and viaducts, and receiving the A26 highway coming from Turin (Italy), as well as the A7 highway coming from Italy's major economic city Milan (Figure 1). Genoa and its region, Liguria, is hostage of gruff, harsh, and, at the same time, wonderful and glamourous territory; mountains plummet into the Mediterranean Sea, flatting the coast like a thin line. Shortly after the bridge collapse, it was clear that the sole possibility for daily movements of some 8,000 heavy goods trucks towards two main basins of the Genoa port, Voltri and Sampierdarena, the main part using the Morandi bridge, was to pile up into the chaotic traffic of the beautiful medieval center trying to flow, facing swarms of zooming scooters. Mayor Bucci immediately affirmed that a new road crossing the city was essential. Near the end of September 2018, the so called "Superba Road" was open; it was built using previously forbidden inner port streets.

Our Neonatal Emergency Transport Service ${ }^{5}$ is based at the Gaslini Children Hospital (hub) in the eastern part of Genoa, and has 10 spoke centers, five of which are in the west side of the Morandi bridge, the western part of the city and Liguria region (Figure 1). We evaluated the ground ambulance round-trip time from Gaslini to the five spoke hospitals in west Liguria, before and after the bridge collapse and after the Superba Road opening, then round-trip time by helicopter (Figure 1). The bridge collapse produced a dramatic extension of trip time; Superba Road significantly reduced post-collapse time $(\mathrm{P}<.01$; Wilcoxon test; Figure 1). Although crossing the city toward the west still remains slow and challenging, we

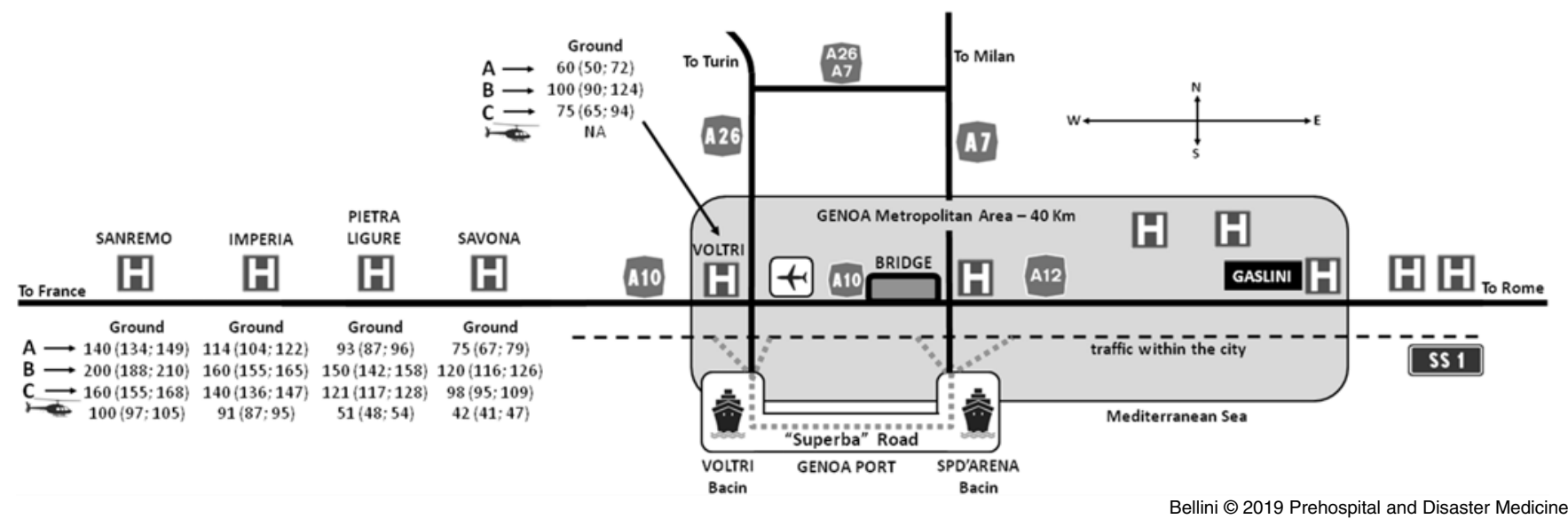

Figure 1. Schematic Geographical Map: (A) Before Collapse; (B) After Collapse; and (C) After Superba Road Opening.

Note: Time in minutes (median and range). 
believe this is an effective improvement and an acceptable result. Obviously, helicopter is the fastest, but unfortunately, it is not always available promptly.
Mayor Bucci ensured that by the end of 2020, Genoa will have the bridge again; this is a long and a short time, simultaneously. All Genoese are fully confident and resolved to never surrender.
References

1. Pianigiani G, Povoledo E, Pérez-Peña R. Cut in two, Genoa finds its political paralysis now eclipsed by shock. The New York Times. https://www.nytimes.com/2018/08/16/ world/europe/genoa-morandi-bridge-political-paralysis.html. Accessed August and December 2018

2. Pianigiani G. "We are tired of crying for the dead:" a stunned Genoa mourns. The New York Times. https://www.nytimes.com/2018/08/15/world/europe/genoa-bridge-scene. html?action\%3Dclick\&module\%3DRelatedCoverage\&pgtype\%3DArticle\&region\% 3DFooter. Accessed August and December 2018

3. Genoa in the eyes of road haulers: "Fewer risks, and work will pick-up again." The Medi Telegraph Shipping \& Intermodal Transport. http://www.themeditelegraph.com/en/ shipping/2018/09/22/genoa-the-eyes-road-hauliers-fewer-risks-and-work-will-pickagain-bifdXkr7NG5X5Ei8h5UUKM/index.html. Accessed September and December 2018

4. Agence France-Press. Genoa bridge disaster: Italian architect Renzo Piano chosen to build replacement. The Guardian. https://www.theguardian.com/world/2018/dec/19/ genoa-bridge-disaster-italian-architect-renzo-piano-chosen-to-build-replacement. Accessed December 2018.

5. Bellini C, Pasquarella M, Ramenghi LA, et al. Evaluation of neonatal transport in European country shows that regional provision is not cost-effective or sustainable and needs to be re-organized. Acta Paediatr. 2018;107(1):57-62. 